\title{
BILLET DEFECTS: PIN-HOLE AND BLOW-HOLE FORMATION, PREVENTION AND EVOLUTION*
}

\author{
Jorge Madias ${ }^{1}$ \\ Alberto Moreno ${ }^{2}$ \\ Cristian Genzano
}

\begin{abstract}
Pin holes as a surface defect, and blow holes as an inner defect, occur in billet / bloom / beam blank casting, particularly for Si-Mn killed steel cast with metering nozzle and oil lubrication. If they are present in abundance or have a large size, they may originate defects in the rolled products. Their characteristics, factors behind their formation, as well as usual processing conditions that promote their occurrence are discussed. Finally, the evolution of these defects during reheating and rolling is analyzed, with industrial examples.
\end{abstract}

Keywords: Billet casting; Metering nozzle; Pin-hole; Blow-hole; Oil lubrication; Nitrogen; Hydrogen; Oxygen. 


\section{INTRODUCTION}

Pin holes as a surface defect, and blow holes as an inner defect, occur in billet / bloom / beam blank casting, particularly for Si-Mn killed steel cast with metering nozzle and oil lubrication. If they are present in abundance or have a large size, they may originate defects in the rolled products. Their characteristics, factors behind their formation, as well as usual processing conditions that promote their occurrence are discussed. Finally, the evolution of these defects during reheating and rolling is analyzed, with industrial examples.

\section{PIN HOLES}

\subsection{Characterization}

They can be seen with naked eye on the as cast surface, although a much better view of this defect is obtained when the billet surface is cleaned of scale by means of sandblasting or shot blasting (figure 1).

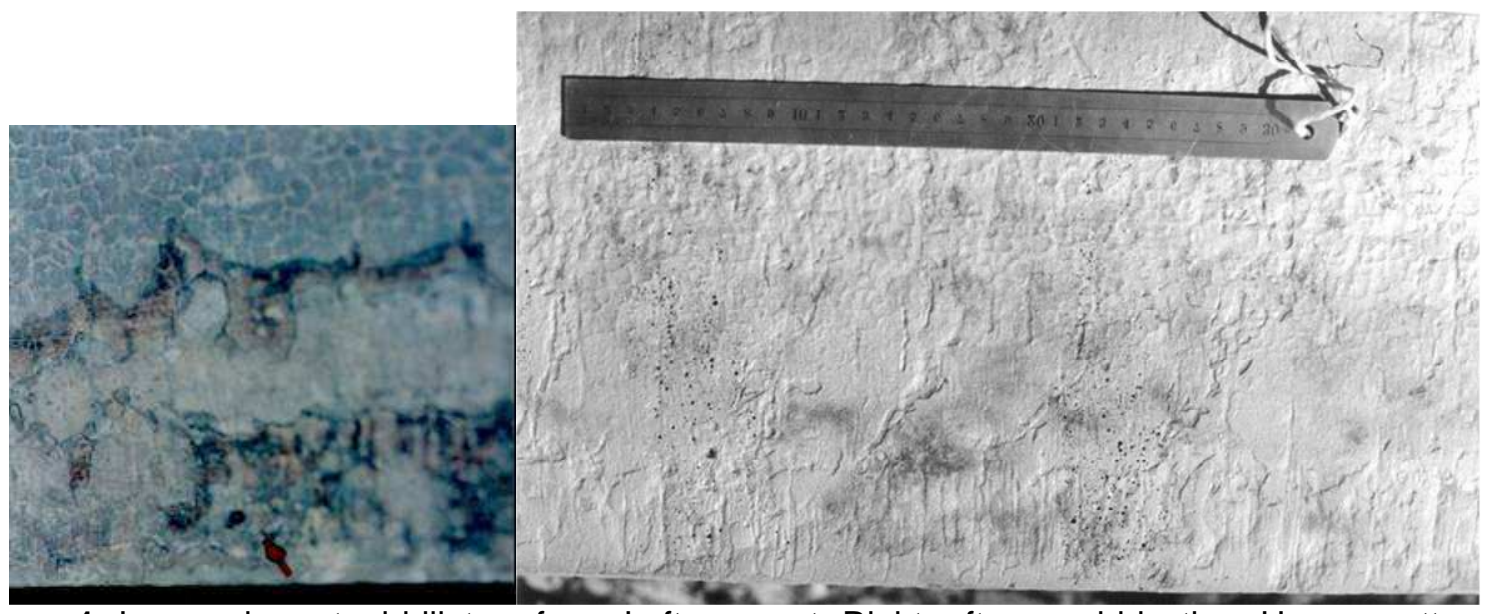

Figure 1. Low carbon steel billet surface. Left: as cast; Right: after sand blasting. Here a pattern of pin-hole occurrence as belts at a certain distance becomes apparent. Oscillation marks are observed only in the part close to the billet corner.

The distribution of the pin-holes on the billet surface depends on the phenomena that originated its formation. While in figure 1 pin-holes occur in transverse belts around the billet, separated by several $\mathrm{cm}$, in figure 2 the pattern is different: the pinholes are accommodated longitudinally along the center of a billet face, while the surface closer to the corner shows some friction-related defects. 


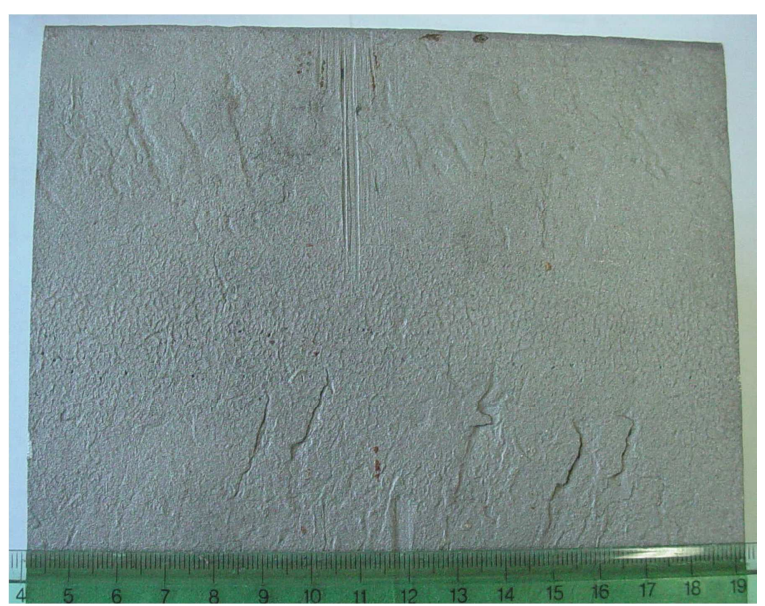

Figure 2. Low carbon steel billet surface, after sand blasting. Pin-holes show up in a longitudinal way in the center of the face. Oscillation marks are slanted and some friction related defects are seen close to one of the corners.

When cutting a metallographic sample perpendicular to the billet surface, the diameter and depth of the pinhole can be observed. A thin layer of scale is present (figure 3). Typically, diameter is larger towards the surface.

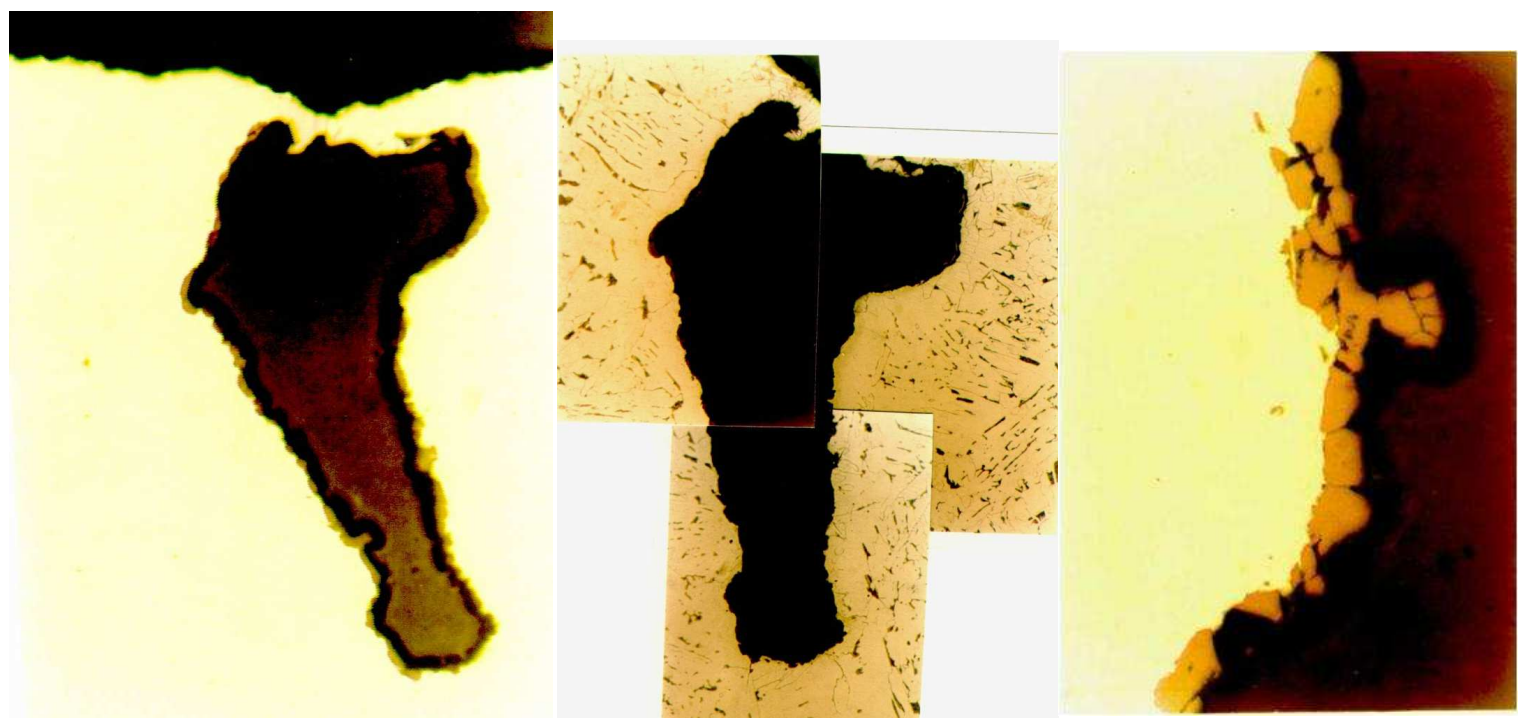

Figure 3. Pin-hole in low carbon steel billet (observation perpendicular to the billet surface). Left: as polished. A burr has formed during polishing, due to the softness of the low carbon steel. Center: metallographic structure after nital etching: ferrite and traces of pearlite. Right: Detail of scale in the pin-hole inner surface.

\subsection{Formation}

The formation of pin holes has been associated with gas development by pyrolysis of lubricating oil, and the presence of oxygen dissolved in the steel.

Friction surface defects are not very sensitive to oil rate (within a certain range). For instance, in figure 4 the results of friction measurements are shown for oil rate varying from 24 to $54 \mathrm{ml} / \mathrm{min}$. Although there is an increase in interaction with lower oil rates, no friction related defects were observed. The same occurred for three different oil types. So, it would be safe to work in the lower range of oil rate, to avoid pin-holing. In practice, 20 to $30 \mathrm{ml} / \mathrm{min}$ is a common figure [1]. 
Often, the problem is not only an excessive oil rate at a given time, but also an inhomogeneous distribution of the oil around the billet section. This fact has been observed mostly for older casters. A divided box located inside the mold during intersequence time let us have an idea of oil distribution. This can be related with pi-holes distribution in the billets (figure 5).

Another important factor in oil distribution is the lubrication slot gap. It is usually recommended to be $1 \mathrm{~mm}$ maximum, in order to keep better homogeneity. The spitting that occurs during casting may partially close the gap, along the sequence. In figure 6 the difference in oil distribution in a given mold before and after corrections in slot opening, and after a sequence is observed.
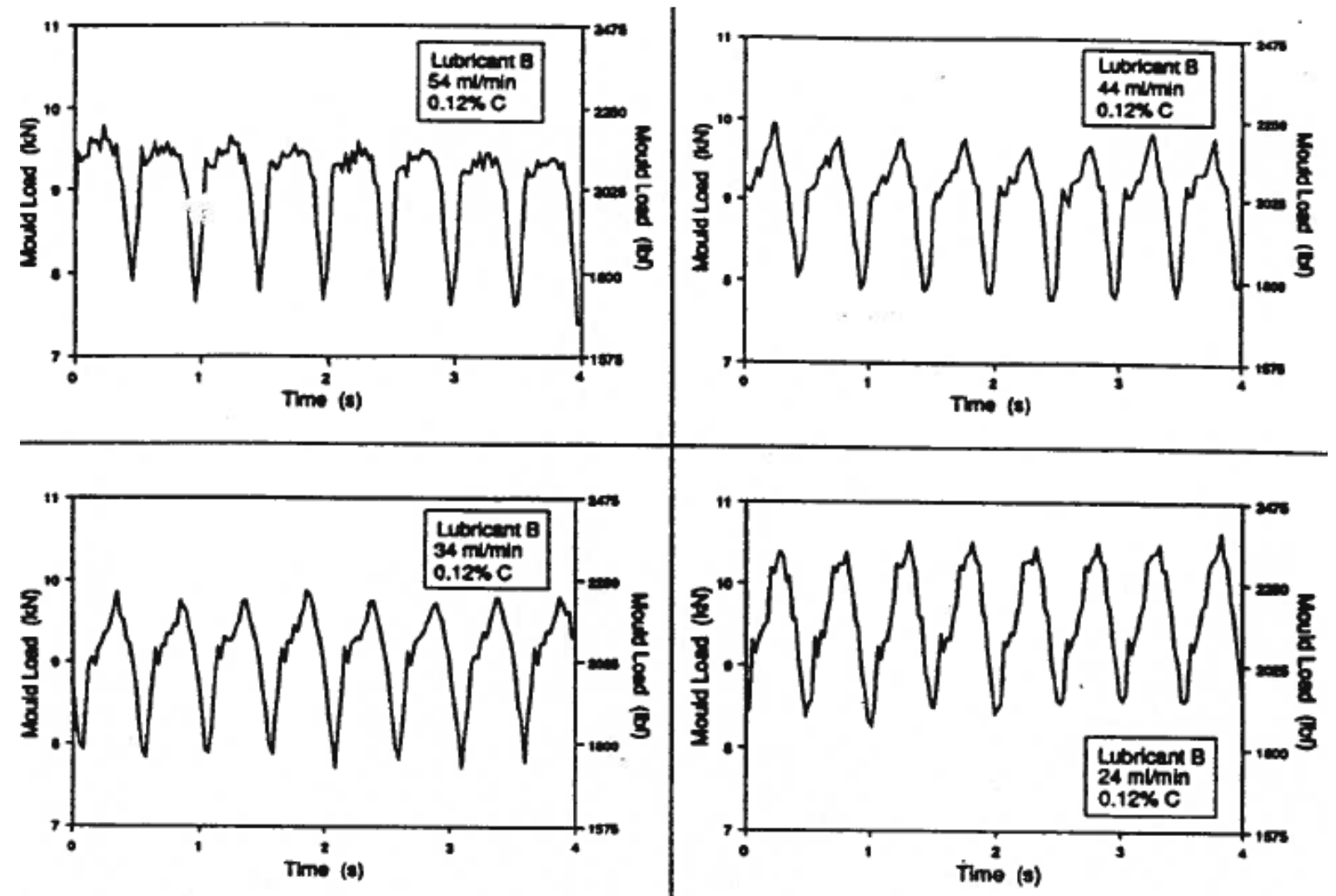

Figure 4. Load cell measurements during casting of low carbon billets with different oil rates [2]. 

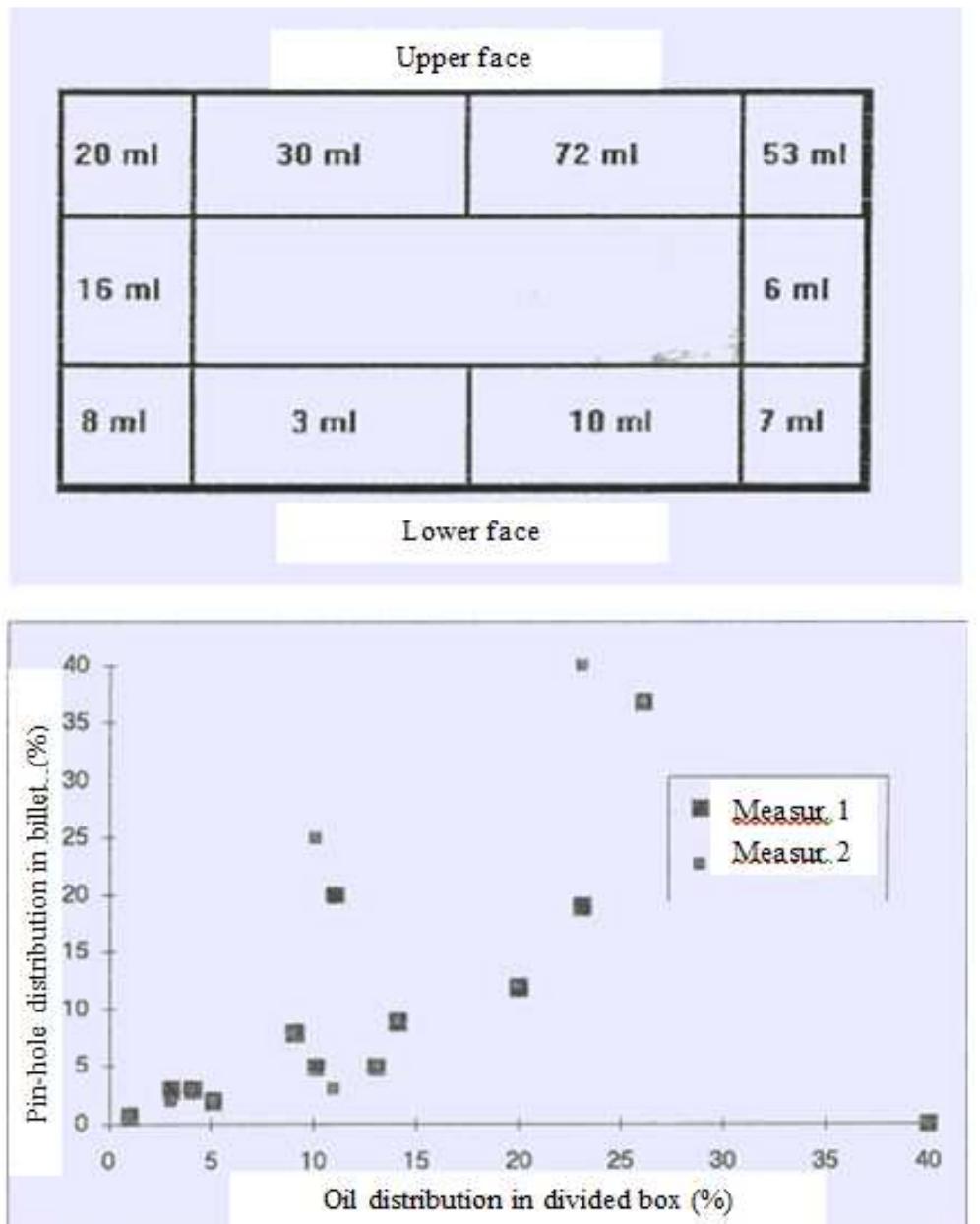

Figure 5. Top: Oil recovered in a divided box located inside the mold during inter-sequence time. Bottom: Influence of oil recovered in each section of the box with pin-holes in the billet cast afterwards [3].
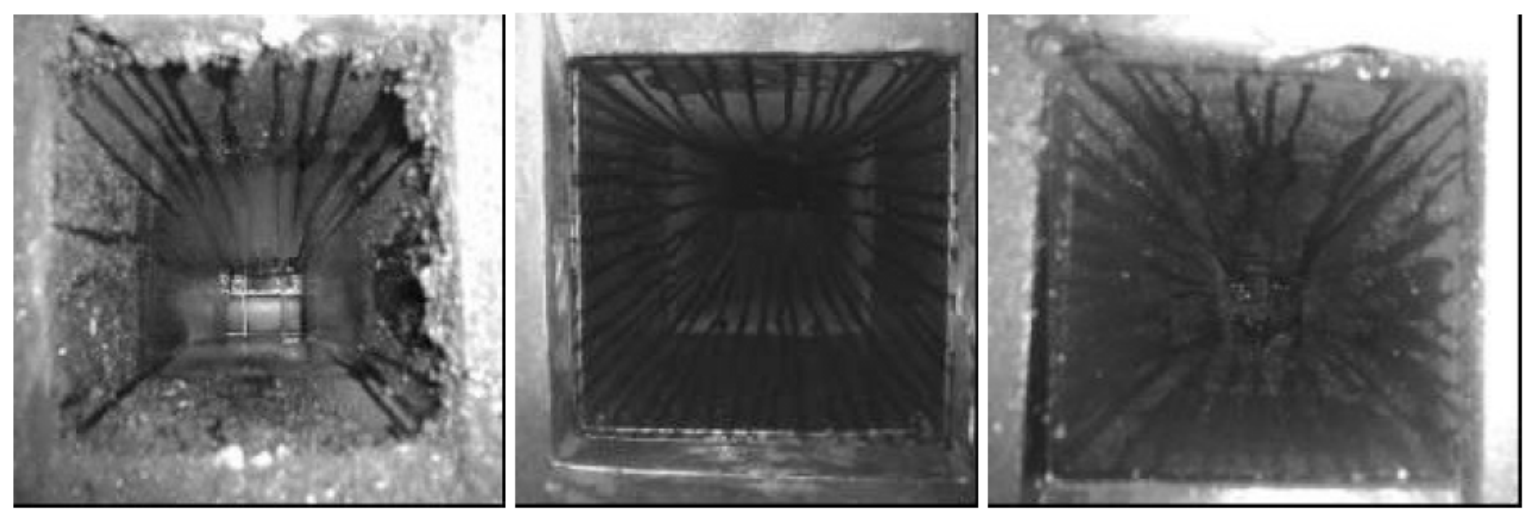

Figure 6. Oil distribution in the mold. Left: before modifications. Center: after modifications (before campaign). Right: after campaign [4].

In relation to the influence of oxygen and other gases dissolved in the steel, generally low carbon steel billets are more affected, as well as the first billets of a casting sequence, submitted to reoxidation and hydrogen pick-up during tundish filling. Moisture in the oil or picked -up in the oil circuit has long being recognized as a factor. Sudden variation of meniscus level is another source of pin holing. 


\subsection{Evolution During Rolling}

There is some discussion on if the pin-holes disappear during reheating, as a side effect of scale formation, or if they become even deeper. In any case the evidence exists that in billets reheated but not rolled, some of the pin-holes remain (figure 7).

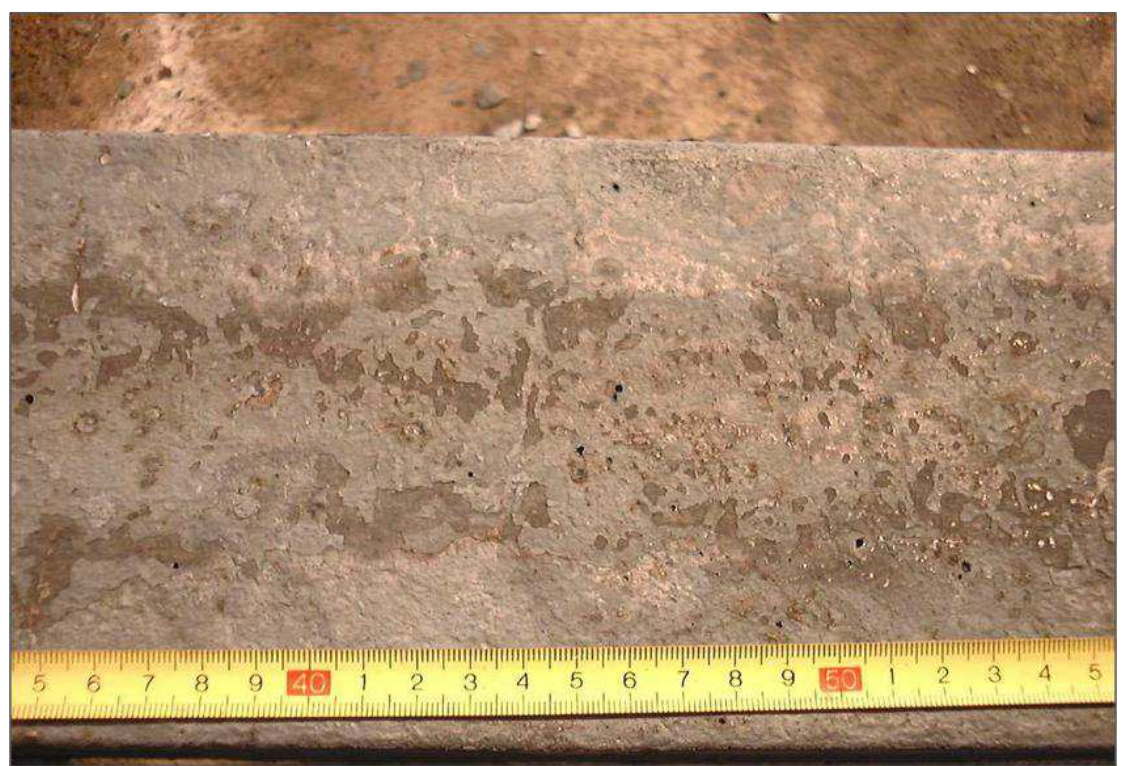

Figure 7. Pin-holes remaining in the surface of a reheated and not rolled billet [4].

After reheating, there is metallographic evidence of the filling with scale (figure 8), as a difference with the as-cast billet (in figure 3 ). During rolling, pin holes elongate. Depending on the reduction, they can be seen on the final product with naked eye or the practically disappear. In figure 9 the aspect of an elongated pin hole is presented in an end crop. The metallographic aspect of the pin hole after rolling, in the final product, has many variations. One particular plant attributes a defect to a previous pin-hole when the scale is thicker in the inside than in the outer part of the defect, as in figure 10.

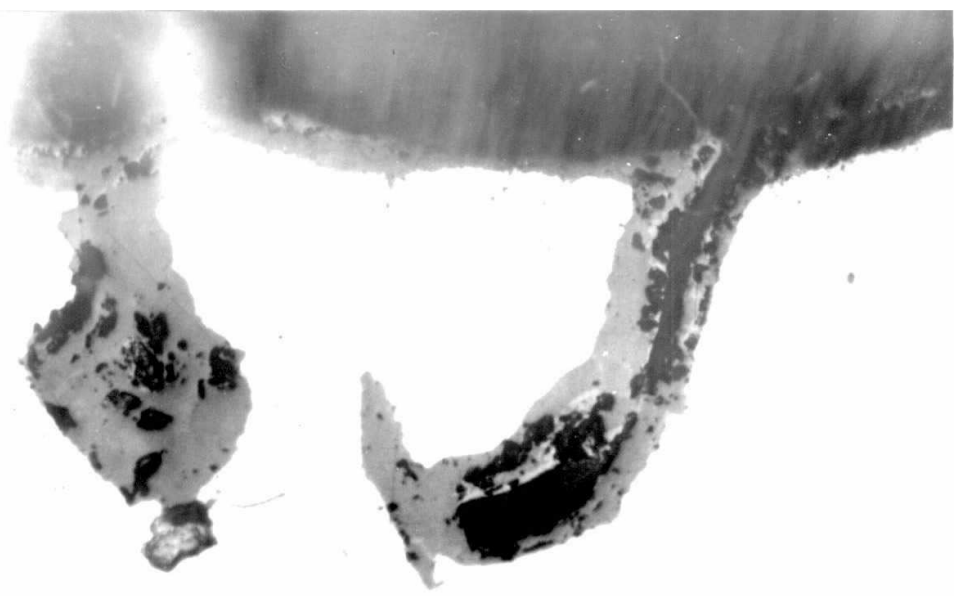

Figure 8. Aspect of a polished cut perpendicular to the billet surface, in a billet submitted to reheating but not rolled. The two pin-holes are filled with scale [4]. 


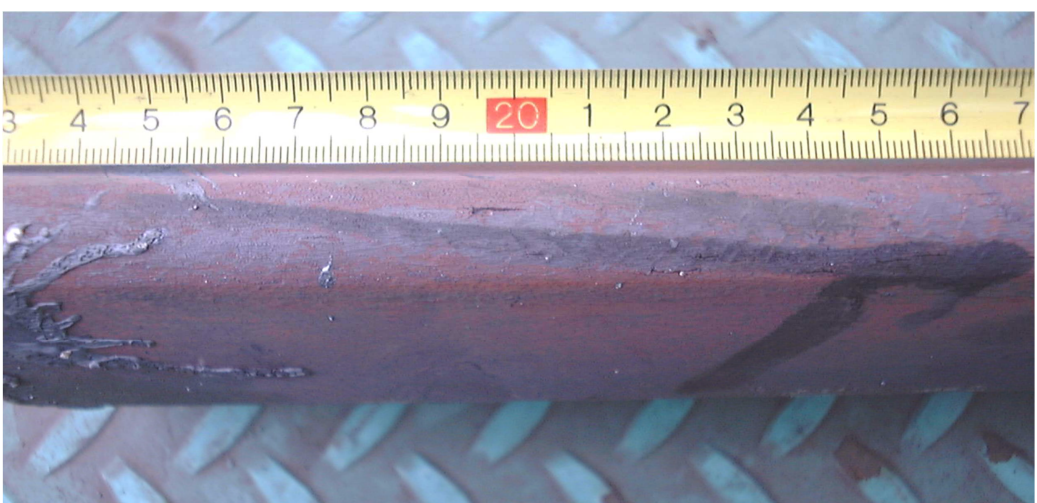

Figure 9. Aspect of an elongated pin-hole in a cropped end of a medium carbon bar stock for rebar [5].

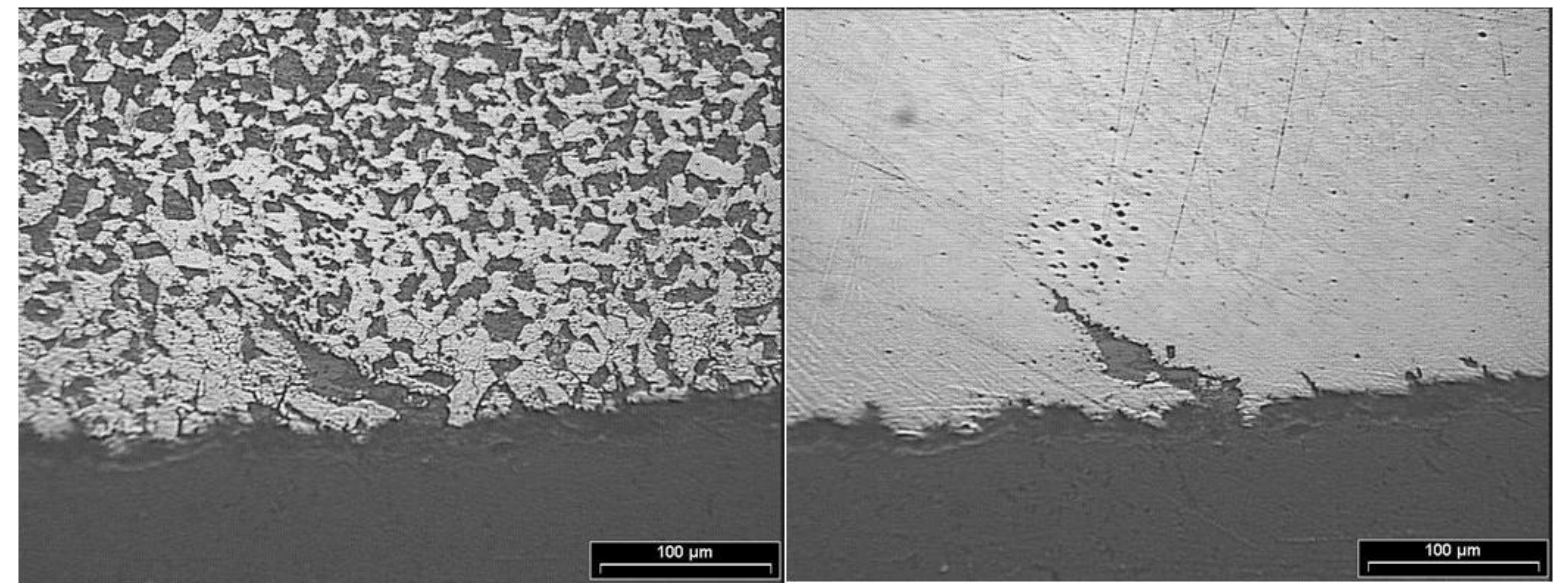

Figure 10. Metallographic aspect of a former pin-hole in a transverse cut of rebar. Left: Nital etching. Right: as polished [5].

\subsection{Countermeasures}

As the origin of these defects is usually traced to oil pyrolysis and secondly to dissolved gases, countermeasures usually taken have to do with these two factors. Automation of the lubrication system, change to vegetable oils modified with esters, proper maintenance of the lubrication circuit from the oil reception to entrance into the mold all point to the first factor. Casters equipped with mold electromagnetic stirring have observed improvement.

Addition of deoxidizers (titanium, as in [6]; aluminum injection into the mold, as in [7]) aims to the second factor. They add cost and may have deleterious side effects (slag patches and breakouts, for aluminum injection) [7]. Avoiding reoxidation by use of ladle shroud and gaseous tundish stream protection adds cost, too, but has other benefits, regarding not only quality but also safety and working environment [8]. As an example, a steel plants reports improvements in pin-holing by decreasing tundish height (shorter tundish to mold stream), changing the type of ladle shroud and by automation of the lubrication system [9]. Another plant using ladle shroud and argon protection for the tundish stream, eliminated aluminum wire injection to avoid slag patches, increasing at the same time aluminum addition at tapping and using $\mathrm{CaSi}$ core wire injection [7]. 


\section{BLOWHOLES}

\subsection{Characterization}

Typically, blowholes are accommodated relatively closed to the billet shell, with a perpendicular direction as in figure 11. They can be seen even in the oxy cut (figure 12). Regarding its distribution (location in the sequence; strands affected; billet / bloom length affected, etc., varies from case to case [10] and depends on the root cause for the excess of gas in the steel.

The metallographic observation shows that the blowholes start in interdendritic regions, and that at their end, there is evidence of their closure by ferrostatic pressure (figure 13). The presence of segregation at the end of the pore is revealed by means of a metallographic etching, for instance with Oberhofer reagent (figure 12).

This association of blowholes and segregation in interdendritic spaces can also be seen in smaller blowholes, like in figure 13. In this case, the small pore is located closed to the corner of a free cutting steel billet that was conditioned by grinding. While with nital etching the segregation is overlooked (figure 12, left), with Oberhofer etching the segregated area is revealed, aligned with the solidification direction.

Several intents of analyzing gas inside blowholes have been carried out. As an example, China Steel researchers obtained an analysis of $90.7 \% \mathrm{H} 2 ; 8.9 \% \mathrm{CH} 4$; $0.4 \% \mathrm{CO} 2$ and $0.2 \% \mathrm{CO}[12]$.

\subsection{Formation}

The generation of blowholes in these steels has been universally attributed to an excess of dissolved gases (oxygen, nitrogen and / or hydrogen, enough to produce a bubble. This process has been modeled from early billet casting times [13], giving a base to an understanding of the phenomena. A result of such modeling is presented in figure 14, showing that:

- Somewhere below the billet shell, the conditions to form the blowholes can be met, for certain amount of dissolved gases;

- Further below the mold, when ferrostatic pressure is higher, partial pressure of dissolved gases is compensated and the blowhole end.
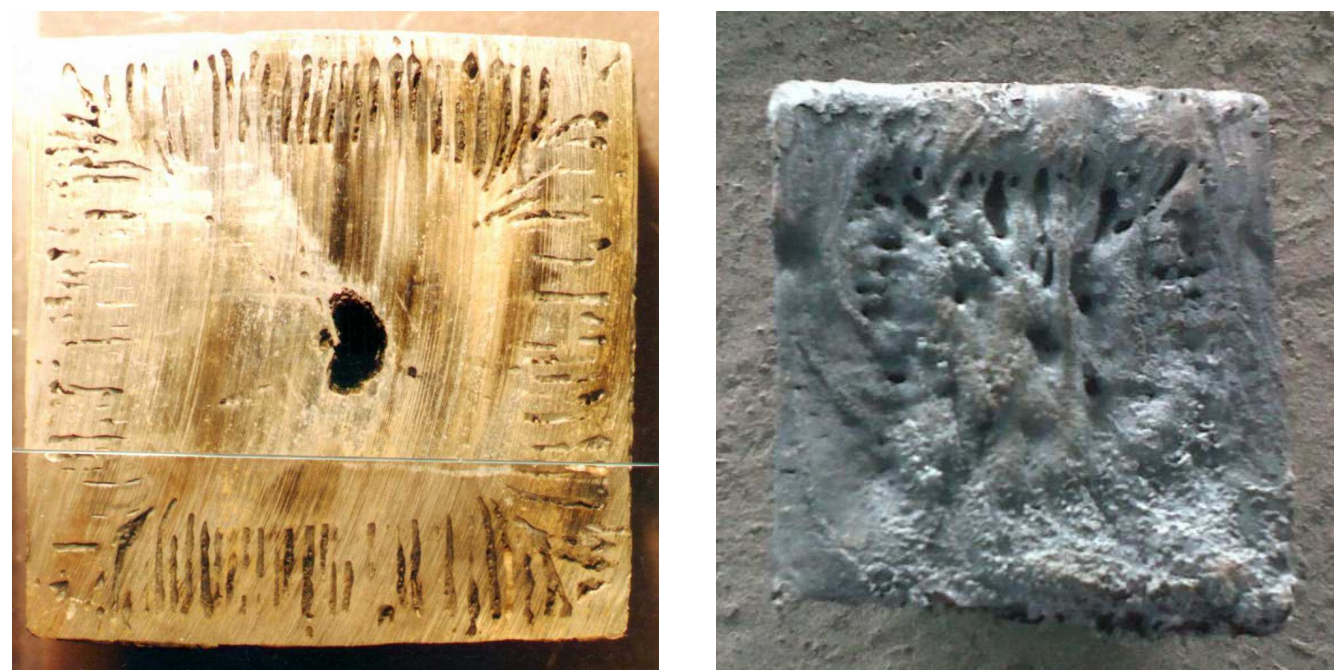

Figure 11. Left: Disk cutting of a carbon steel billet with blowholes [11]. Right: Oxygen cutting of a carbon steel billet with blowholes. 

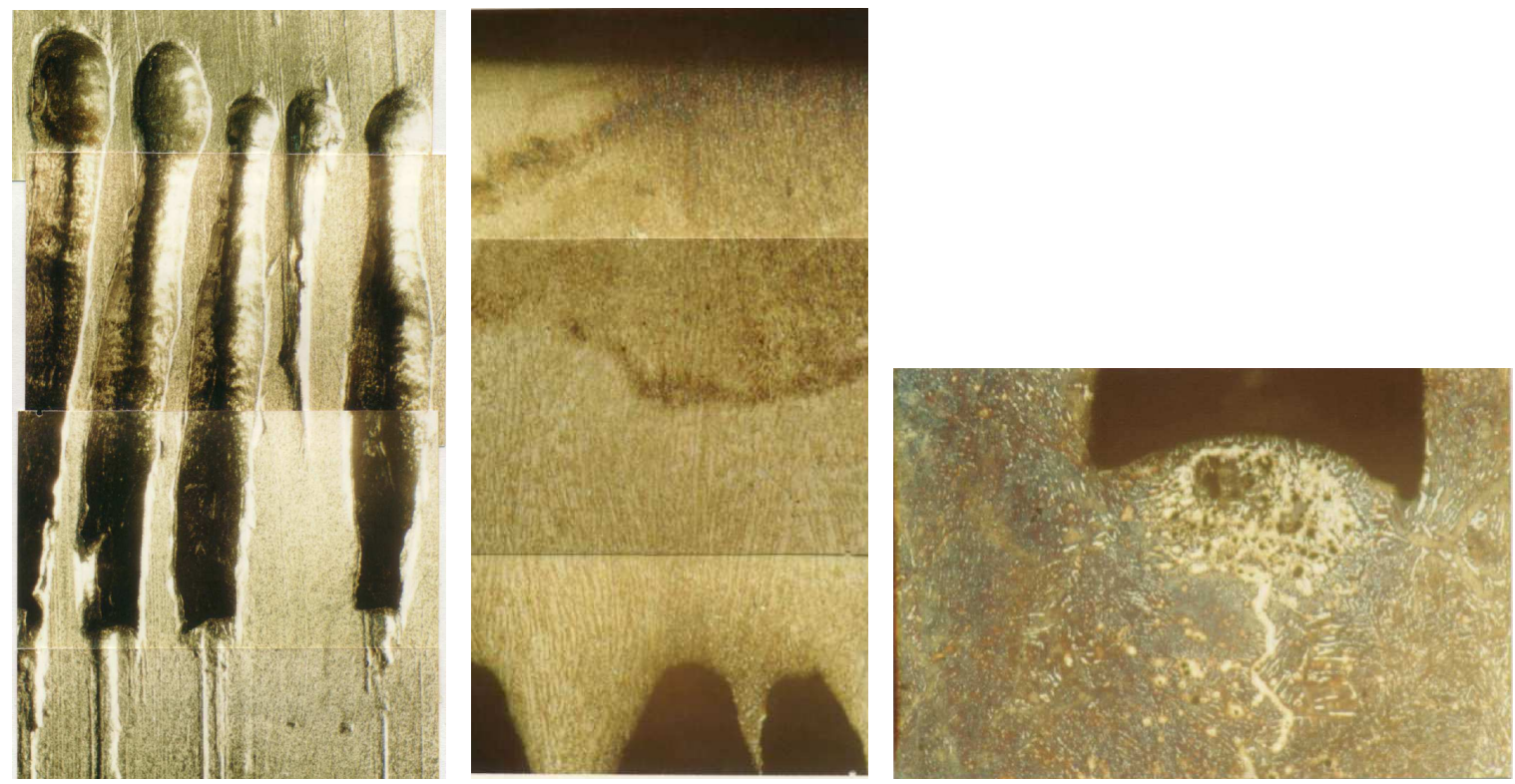

Figure 12. Left: Detail of the blowholes in figure 11. Center: Structure of the billet, from the skin to the initial formation of the blowholes. Oberhofer etching. Right: Structure in the lower part of the blowhole, showing the closure effect of the ferrostatic pressure and the segregated region below the blowhole. Oberhofer etching [11].

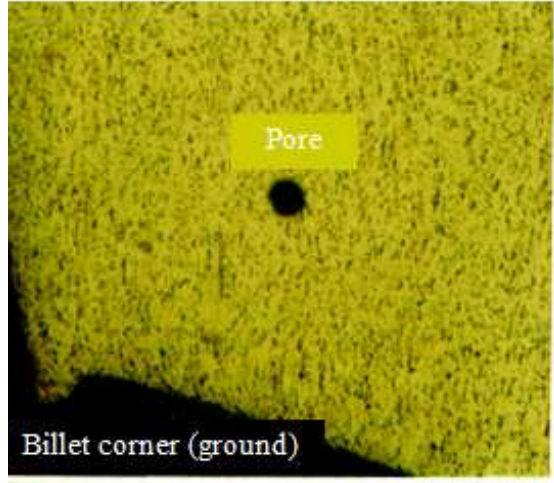

Nital $2 \%$

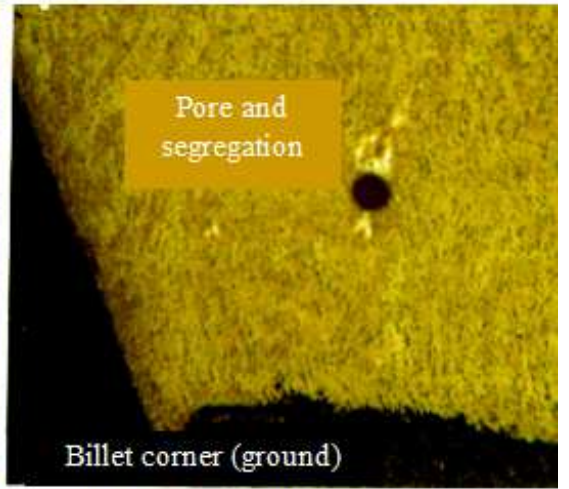

Oberhofer

Figure 13. Transverse cut of a free cutting steel billet corner, showing a small pore.

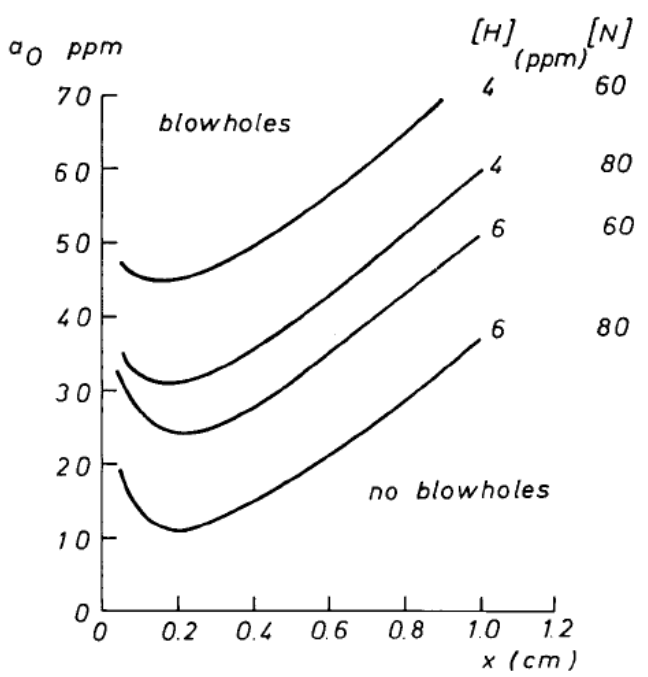

Figure 14. Application of modeling of blowhole formation to a typical low carbon steel: $0.05 \% \mathrm{C}, 0.4^{\circ}$ $\mathrm{Mn}$ [13]. 


\subsection{Evolution during rolling}

These defects, if not in contact with the surface, will not develop scale during reheating, as opposite to pin holes. So, they may weld partially or totally during rolling. But it must not be forgotten that segregation is associated with them and may cause trouble in certain applications. This segregation is often seen in the transverse metallographic cut of rolled products as ghost lines. They could also arise from other segregation-related defects, like midway and off-corner cracks. In the risk of giving place to a defect, if the occurrence of blowholes in certain situations is endemic, an improvement plan should be designed and carried out.

\subsection{Countermeasures}

Minimizing the occurrence of the blowholes is a question of constant and uniform operating practices (in a broad sense, including ladle and tundish lining preparation as well as lime handling) avoiding the reasons for high oxygen, nitrogen or hydrogen in the steel. This means dry lime (or partial use of sintered lime) in the ladle; low furnace slag carry-over; an even deoxidation practice that avoids dispatching undeoxidized or over-deoxidized ladles to the caster, avoiding long treatment times, and switching to argon when this occurs; tundish and ladle without remaining moisture, etc. Three typical operating situations where blowholes may be observed are as follows:

- Heat sent to the caster when deoxidation was not still finished, due for instance to coordination reasons or difficult deoxidation related to slag carry over.

- Start of a sequence. Here the oxygen and nitrogen picked-up by contact with air during tundish filling may be enhanced by moisture remaining in the tundish lining

- New ladle with some moisture remaining in the lining

- Ladle with long treatment time, when just nitrogen is used as stirring gas.

As an example, in the case of a beam blank caster it was found that the main contributor to blowhole formation was hydrogen from the sealing material for tundish lining [12]. In another case, the focus was on improving deoxidation and avoiding reoxidation [14].

\section{CONCLUSIONS}

Pin holes and blow holes are typical defects that occur in Si-Mn killed steel cast with metering nozzle and oil lubrication. Although in both cases, the root cause for their formation is gas evolution, the mechanisms are somewhat different. In the formation of pin holes, the gas generated by the pyrolysis of the lubricating oil seems to be the most important factor. Nevertheless, some synergy with gases dissolved in the steel might be possible. Instead, blow holes for theses steels are originated in gases dissolved in the steel that segregate to interdendritic space and if their partial pressure is enough, form bubbles. For the bubbles to develop, besides a high content in dissolved gas, segregation of gases to interdendritic spacing is required, a condition that is not met at the surface, but to some depth inside the billet. Although these billet defects not always give place to defects in the rolled products, their occurrence must be closely followed and avoided. 


\section{REFERENCES}

1 I.A. Bakshi; J.L. Brendzy; N. Walker; S. Chandra; I.V. Samarasekera; J.K. Brimacombe; Mold-strand interaction in continuous casting of steel billets Part 1 Industrial trials. Ironmaking \& Steelmaking Vol. 20, 1993.

2 S. Chandra; Heat transfer, mold lubrication and mold tapers in steel billets casting machine, PhD Thesis, University of British Columbia, May 1992.

3 W. Santamaria; J. Madias; A. Moreno; Study of oil distribution in a mini slab mold. 1st and 2nd report, April 1995.

4 A. Barrientos; L. Osorio; N. Dieter; P. Silva; C. Genzano; M. Dziuba; Minimization of surface defects in reinforcing bars. 14th IAS Rolling Conference, 2002, San Nicolas, Argentina, pp. 257-264.

5 C. Genzano, L. Reda, J. Madias; Minimization of surface defects on bars and wire rod originated in billet casting. 34th ABM Steelmaking Seminar, May 2003, Belo Horizonte, Brazil, pp. 386-395.

6 K. Kunkel.; N. Franzen; H. Jackson; J. Buss; J. Marshall; Titanium - powerful tool in eliminating pinhole defects and improving product yield. 1993 Electric Furnace Conference Proceedings, pp. 245-250.

7 D. Michishita, Y. Udo, M. Ono, T. Idesako; Quality improvement of billet for wire rods. AISTech 2013 Proceedings, pp. 1853-1858.

8 J. Madias; A. Moreno; Strategies against reoxidation of liquid steel in billet casting with metering nozzle. AISTech 2014 Proceedings, pp. 1771-1778.

9 Decreasing the cost of billet conditioning for elimination of surface defects. Report on improvement plan, Aceros Arequipa, Pisco, Peru, May 2009, pp. 1-44 (in Spanish).

10 D. Pihura; Blowholes in continuous cast blooms. Kovine, Zlitine, Tehnologije 33 (1999) 6, pp. 531-533.

11 J. Madias, A. Moreno. Continuous casting of billets and blooms. Course notes, metallon, October 2014.

12 Ch.-Y. Chen; K.-Y. Lin; Forming factors of blowhole defect in continuously cast beam blank at Dragon Steel. China Steel Technical Report 2011, No. 24, pp. 7-13.

13 A. Palmaers; J. Defays; L. Philippe; Deoxidation of continuously cast low carbon steel for billets .C.R.M. Bulletin No 55 November 1979, pp. 16-23.

14 R. Kumari; E.Z. Chakg; R.B.V. Ramana; B. Ghosh; A. Sukapuntavorn; Th. Lertsirarungsun. Improvement in the quality of as-cast high carbon billets at Tata Steel Thailand. SEAISI Quarterly Journal 2012, Vol. 21 No. 7, pp. 19-25. 